\title{
Peripheral Vascular Anomalies - Essentials in Periinterventional Imaging
}

\section{Periphere kongenitale Gefäßanomalien - Grundlagen der periinterventionellen Bildgebung}

Authors

Maliha Sadick ${ }^{1}$, Daniel Overhoff ${ }^{1}$, Bettina Baessler ${ }^{1}$, Naema von Spangenberg ${ }^{1}$, Lena Krebs ${ }^{1}$, Walter A. Wohlgemuth ${ }^{2}$

Affiliations

1 University Medical Center Mannheim, Institute for Clinical Radiology and Nuclear Medicine, Mannheim, Germany

2 Department for Radiology, Martin-Luther-Universität Halle-Wittenberg, Halle, Germany

Key words

blood vessels, angiography, diagnostic radiology, embolization, interventional procedures, CT angiography

received 01.06.2019

accepted 04.08.2019

\author{
Bibliography \\ DOI https://doi.org/10.1055/a-0998-4300 \\ Published online: 17.10.2019 \\ Fortschr Röntgenstr 2020; 192: 150-162 \\ (c) Georg Thieme Verlag KG, Stuttgart · New York \\ ISSN 1438-9029
}

\section{Correspondence}

Prof. Maliha Sadick

University Medical Center Mannheim, Institute for Clinical Radiology and Nuclear Medicine, Theodor-Kutzer-Ufer 1-3, 68167 Mannheim, Germany

Tel.: ++49/621/3832067

Fax: $++49 / 621 / 383734577$

maliha.sadick@umm.de

\section{ZUSAMMENFASSUNG}

Hintergrund Periphere Gefäßanomalien sind eine seltene Erkrankung, die auf einer kongenitalen Störung der mesenchymalen und angiogenetischen Entwicklung von Gewebe basiert. Gefäßanomalien werden in Gefäßtumoren und vaskuläre Malformationen unterteilt. Beide Entitäten sind mit charakteristischen Flusseigenschaften vergesellschaftet. Symptome können im Kindes- und Erwachsenenalter manifest werden. Gefäßanomalien gehen mit klinischen Befunden einher, die die Diagnose erleichtern können. Die Rolle der periinterventionellen Bildgebung besteht in der Bestätigung der klinischen Verdachtsdiagnose unter Berücksichtigung von Ausdehnung und Lokalisation der Gefäßanomalie.

Material und Methode In Anlehnung an die International Society for the Study of Vascular Anomalies (ISSVA) werden
Gefäßanomalien in Slow-flow- und Fast-flow-Läsionen eingeteilt. Basierend auf Diagnose und Flussdynamik wird für die Gefäßanomalien die am besten geeignete Bildgebung beschrieben. Das gesamte Spektrum der Bildgebung umfasst Ultraschall, konventionelles Röntgen, CT und MRT sowie die perkutane Phlebografie und die Katheterangiografie. Gefäßanomalien bedürfen einer dezidierten Bildgebung. Die Einteilung in Slow-flow- und Fast-flow-Entitäten erleichtert die Auswahl der diagnostischen Modalitäten.

Ergebnisse Slow-flow-Gefäßanomalien beinhalten venöse, lymphatische und kombinierte Gefäßanomalien. Ultraschall und MRT, insbesondere die MR-Venografie, sind essenziell für die Diagnostik von Slow-flow-Gefäßanomalien. Arteriovenöse Malformationen sind Fast-flow-Gefäßanomalien. Diese sollten mit dedizierten MRT-Protokollen untersucht werden, insbesondere dann, wenn es sich um ausgedehnte Gefäßanomalien handelt. Die 4D-CT-Bildgebung und zeitaufgelöste 3D-MRA ermöglichen multiplanare Perfusionsuntersuchungen. Diese Modalitäten sollten der Behandlungsplanung vorbehalten sein, da sie die Interventionszeit beachtlich verkürzen können. Fast-flow-Gefäßtumoren, wie z. B. Hämangiome, sollten mittels Ultraschalls, Duplexsonografie und MRT evaluiert werden. Die Katheterangiografie kommt bei geplanter Embolo-Therapie zum Einsatz. Bei Malformationssyndromen muss die radiologische Bildgebung stets nach der dominierenden vaskulären Komponente der Gefäßanomalie selektioniert werden.

Zusammenfassung Diese Übersichtsarbeit unterteilt periphere Gefäßanomalien, nämlich vaskuläre Malformationen und vaskuläre Tumoren, anhand ihrer Flussdynamik und empfiehlt geeignete periinterventionelle Bildgebungsmethoden zur Optimierung von Diagnostik und Therapie dieser seltenen Erkrankung.

\section{Kernaussagen:}

- Periphere Gefäßanomalien sind eine Seltene Erkrankung, die auf einer kongenitalen Störung der mesenchymalen und angiogenetischen Entwicklung von Gewebe basiert

- Die Rolle der periinterventionellen Bildgebung liegt in der Diagnosesicherung anhand der Flussdynamik der Gefäßanomalie

- Slow-flow Gefäßanomalien beinhalten venöse, lymphatische und kombinierte Gefäßanomalien. Arteriovenöse Malformationen sind fast-flow Gefäßanomalien, wohingegen Hämangiome fast-flow Gefäßtumore sind, die oftmals 
auch mit ausgedehnten arteriovenösen fast-flow shunts einhergehen. Die periinterventionelle Bildgebung umfasst eine Vielzahl von diagnostischen Optionen, darunter dedizierte MRT Protokolle, 4D CT Bildgebung und Katheterangiographie

\section{ABSTRACT}

Background Peripheral vascular anomalies represent a rare disease with an underlying congenital mesenchymal and angiogenetic disorder. Vascular anomalies are subdivided into vascular tumors and vascular malformations. Both entities include characteristic features and flow dynamics. Symptoms can occur in infancy and adulthood. Vascular anomalies may be accompanied by characteristic clinical findings which facilitate disease classification. The role of periinterventional imaging is to confirm the clinically suspected diagnosis, taking into account the extent and location of the vascular anomaly for the purpose of treatment planning.

Method In accordance with the International Society for the Study of Vascular Anomalies (ISSVA), vascular anomalies are mainly categorized as slow-flow and fast-flow lesions. Based on the diagnosis and flow dynamics of the vascular anomaly, the recommended periinterventional imaging is described, ranging from ultrasonography and plain radiography to dedicated ultrafast CT and MRI protocols, percutaneous phlebography and transcatheter angiography. Each vascular anomaly requires dedicated imaging. Differentiation between slowflow and fast-flow vascular anomalies facilitates selection of the appropriate imaging modality or a combination of diagnostic tools.

Results Slow-flow congenital vascular anomalies mainly include venous and lymphatic or combined malformations. Ultrasound and MRI and especially MR-venography are essential for periinterventional imaging. Arteriovenous malformations are fast-flow vascular anomalies. They should be imaged with dedicated MR protocols, especially when extensive. CT with 4D perfusion imaging as well as time-resolved 3D MR-A allow multiplanar perfusion-based assessment of the multiple arterial inflow and venous drainage vessels of arterio-venous malformations. These imaging tools should be subject to intervention planning, as they can reduce procedure time significantly. Fast-flow vascular tumors like hemangiomas should be worked up with ultrasound, including color-coded duplex sonography, MRI and transcatheter angiography in case of a therapeutic approach. In combined malformation syndromes, radiological imaging has to be adapted according to the dominant underlying vessels and their flow dynamics.

Conclusion Guide to evaluation of flow dynamics in peripheral vascular anomalies, involving vascular malformations and vascular tumors with the intention to facilitate selection of periinterventional imaging modalities and diagnostic and therapeutic approach to vascular anomalies.

\section{Key Points:}

- Peripheral vascular anomalies include vascular malformations and vascular tumors. Both entities represent a rare disease with an underlying congenital mesenchymal or angiogenetic disorder

- The role of periinterventional imaging is confirmation of the diagnosis by assessing the flow dynamics of the vascular anomaly

- Slow-flow congenital vascular anomalies include venous, lymphatic and venolymphatic malformations. Arteriovenous malformations are fast-flow vascular anomalies, whereas hemangiomas are fast-flow vascular tumors that are frequently associated with fast-flow arteriovenous shunts. The periinterventional imaging modalities of choice include dedicated MR protocols and CT with 4D perfusion imaging as well as invasive transcatheter angiography.

\section{Citation Format}

- Sadick M, Overhoff D, Baessler B et al. Peripheral Vascular Anomalies - Essentials in Periinterventional Imaging. Fortschr Röntgenstr 2020; 192: 150-162

\section{Introduction}

Peripheral vascular anomalies are a rare disease based on a congenital disorder of vasculogenesis and angiogenesis [1, 2]. They are heterogeneous in appearance and can be located in the head and neck region (40\%), the upper and lower extremities (35\%), chest and trunk (15\%) but can also become manifest in the gastrointestinal and urogenital tract (10\%) [3-5]. Treating physicians, surgeons and diagnostic and interventional radiologists have to be familiar with the disease classification [6]. Periinterventional imaging plays a mandatory role in the diagnostic characterization of vascular anomalies, the assessment of flow dynamics and the provision of customized therapy [7, 8]. As general knowledge on the vasculature of this rare disease is limited, standardized diagnostic algorithms and imaging protocols are required to assure appropriate diagnosis in combination with the clinical manifesta- tion of each vascular anomaly. Characteristic flow dynamics help to depict the underlying vascular anomaly. The role of imaging is to confirm the diagnosis, as precisely as possible.

The classification of vascular anomalies into vascular tumors and vascular anomalies according to ISSVA (International Society for the Study of Vascular Anomalies) and DiGGefA (Deutsche interdisziplinäre Gesellschaft für Gefäßanomalien) has already been described in previous publications $[1,2,9,10]$. The division of vascular anomalies into slow-flow and fast-flow lesions has a high impact on therapy decisions, which range from oral pain therapy and anticoagulation to sclerotherapy procedures in venous and lymphatic malformations and complex catheter embolization treatment in arteriovenous malformations [11].

Periinterventional imaging should verify the clinically suspected diagnosis of a vascular anomaly and provide sufficient information for precise treatment planning $[12,13]$. The goal of this over- 
- Table 1 Flow-related Spectrum of Imaging Modalities in Peripheral Vascular Anomalies.

- Tab.1 Spektrum der Bildgebung von Gefäßanomalien und ihrer Flusscharakteristika.

\begin{tabular}{|c|c|c|c|}
\hline flow-characteristic & type & imaging modality & diagnostic outcome \\
\hline \multirow[t]{4}{*}{ FAST-FLOW } & hemangioma (Vascular Tumor) & ultrasound & +++ \\
\hline & & color doppler scan & +++ \\
\hline & & MRI and MR-A & ++ \\
\hline & & catheter angiography & + \\
\hline \multirow[t]{5}{*}{ FAST-FLOW } & arteriovenous malformation & ultrasound & + \\
\hline & & color doppler scan & +++ \\
\hline & & MRI and MR-A & ++ \\
\hline & & ${ }^{*}$ perfusion $\mathrm{CT}$ with $\mathrm{CT}-\mathrm{A}$ & +++ \\
\hline & & catheter angiography & +++ \\
\hline \multirow[t]{5}{*}{ SLOW-FLOW } & venous malformation & ultrasound & +++ \\
\hline & & color doppler scan & + \\
\hline & & conventional X-Ray & + \\
\hline & & MRI and MR-V & +++ \\
\hline & & transvenous phlebography & +++ \\
\hline \multirow[t]{2}{*}{ SLOW-FLOW } & lymphatic malformation & ultrasound & +++ \\
\hline & & MRI & ++ \\
\hline \multicolumn{4}{|c|}{$\begin{array}{l}\text { MRI: Magnetic Resonance Imaging, MRA: Magnetic Resonance Angiography, MRV: Magnetic Resonance Venography, CT: Computed Tomography, } \\
\text { CTA: Computed Tomography Angiography. Diagnostic Outcome: +++ very high, ++ high, + moderate. } \\
\text { MRT = Magnetresonanztomografie; MRA = Magnetic Resonance-Angiografie; MRV = Magnetic Resonance-Venogrfhie; CT = Computertomografie; } \\
\text { CTA = Computertomografie-Angiografie. Diagnostisches Outcome: }+++ \text { sehr hoch, }++ \text { hoch, + moderat. } \\
\text { "Perfusion CT with Time-resolved 4D-CT-Angiography (4 D CTA) should be considered as an integral part of therapy planning in extensive fast-flow } \\
\text { AVMs. Overall assessment of the AVM, navigation to access routes during embolization procedure, choice of embolic agents and catheter devices may } \\
\text { be facilitated for treatment. }\end{array}$} \\
\hline
\end{tabular}

view of the essentials in periinterventional imaging of peripheral vascular anomalies is to simplify the diagnostic approach and the interdisciplinary management of this rare disease.

\section{Flow Characterization of Vascular Anomalies}

Vascular anomalies comprise a wide spectrum of vascular tumors and vascular malformations. Amongst the large variety of vascular tumors, hemangiomas are the most frequent representative of benign lesions in neonates and infants and they are typically fast-flow vascular tumors $[6,7,14]$.

Simple vascular malformations include arteriovenous (8\%), venous (72\%), lymphatic (10\%) and capillary (10\%) malformations [14]. Like hemangiomas, arteriovenous malformations are fastflow vascular anomalies, while venous and lymphatic malformations are considered slow-flow lesions. As capillary malformations are subject to clinical diagnosis, commonly appearing as naevus flammeus or port-wine staining, they will not be discussed in this overview.

This overview is going to emphasize on periinterventional imaging of the most common peripheral vascular anomalies that can be a challenge for any physician dealing with them. Syndromal vascular anomalies that combine multiple vessels are not included. For further details on the complete classification of vascular anomalies, we refer to our previous publication and the ISSVA and DiGGefA classification [6, 7, 14].

\section{Flow-related Spectrum of Imaging Modalities in Peripheral Vascular Anomalies}

If characterized according to their flow dynamics, peripheral vascular anomalies can be divided into two major groups: fast-flow lesions, including infantile hemangiomas (vascular tumor) and arteriovenous malformations (AVM), and slow-flow lesions, including venous (VM) and lymphatic (LM) malformations. An overview of the recommended imaging spectrum for vascular anomalies, according to their individual flow characteristics, is presented in - Table 1.

\section{Grayscale Ultrasound and Color-Coded Duplex Sonography}

Fast-flow hemangiomas usually appear as compact echogenic lesions with rich vascular density and dominant high-velocity 
SLOW-FLOW VENOUS MALFORMATIONS (Vascular Anomaly)

SLOW-FLOW Venöse Malformationen (Gefäßanomalie)

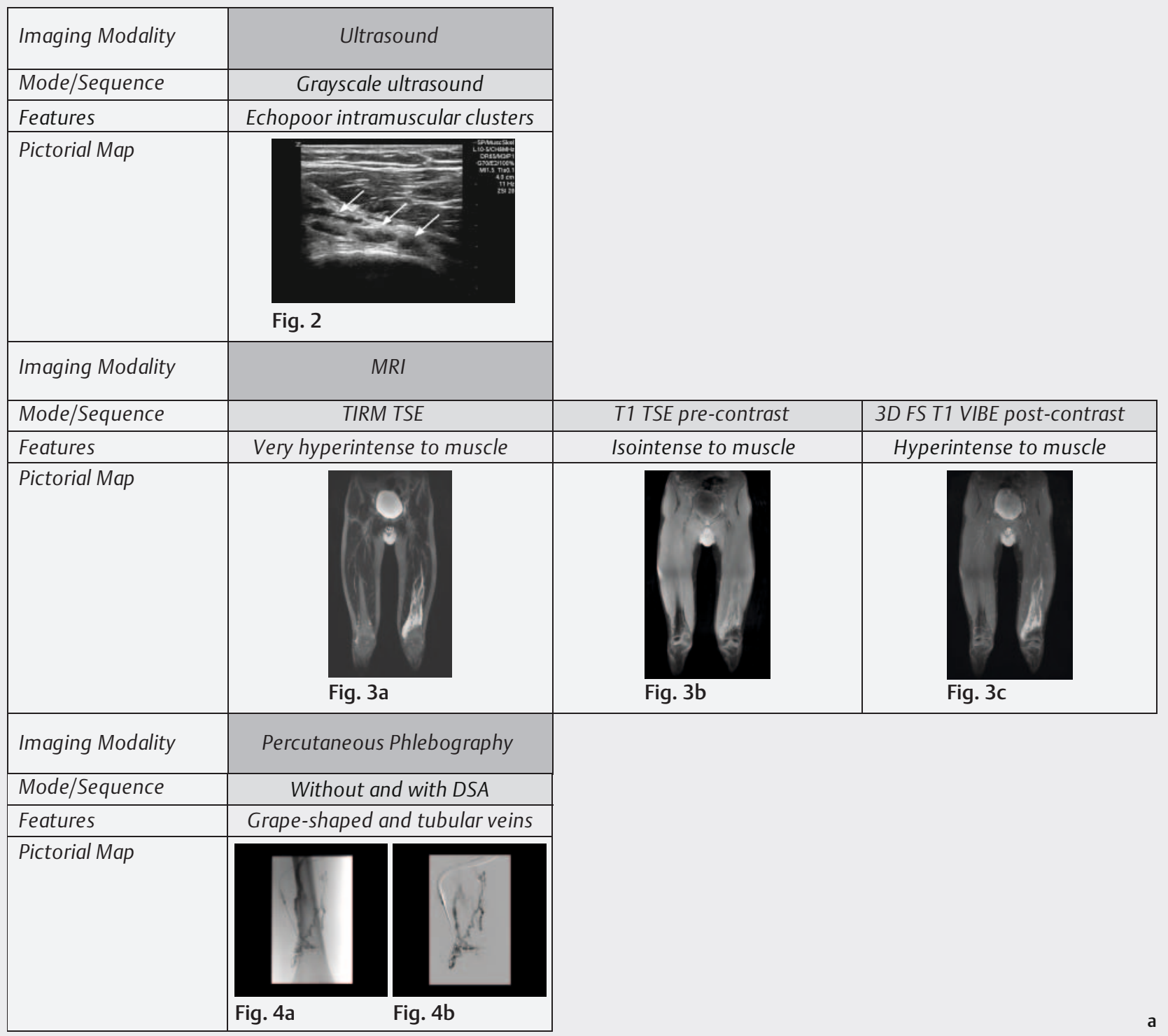

- Fig. 1 a-c Features of Peripheral Vascular Anomalies on Dedicated Imaging with Pictorial Overview. a Slow-Flow Venous Malformations (Vascular Anomaly).

- Abb. 1 a-c Merkmale peripherer Gefäßanomalien anhand dedizierter Bildgebung und Bildbeispielen. a Slow-Flow-venöse Malformationen (Gefäßanomalie). 


\section{FAST-FLOW ARTERIO-VENOUS MALFORMATIONS (Vascular Anomaly)}

\section{FAST-FLOW Arteriovenöse Malformationen (Gefäßanomalie)}

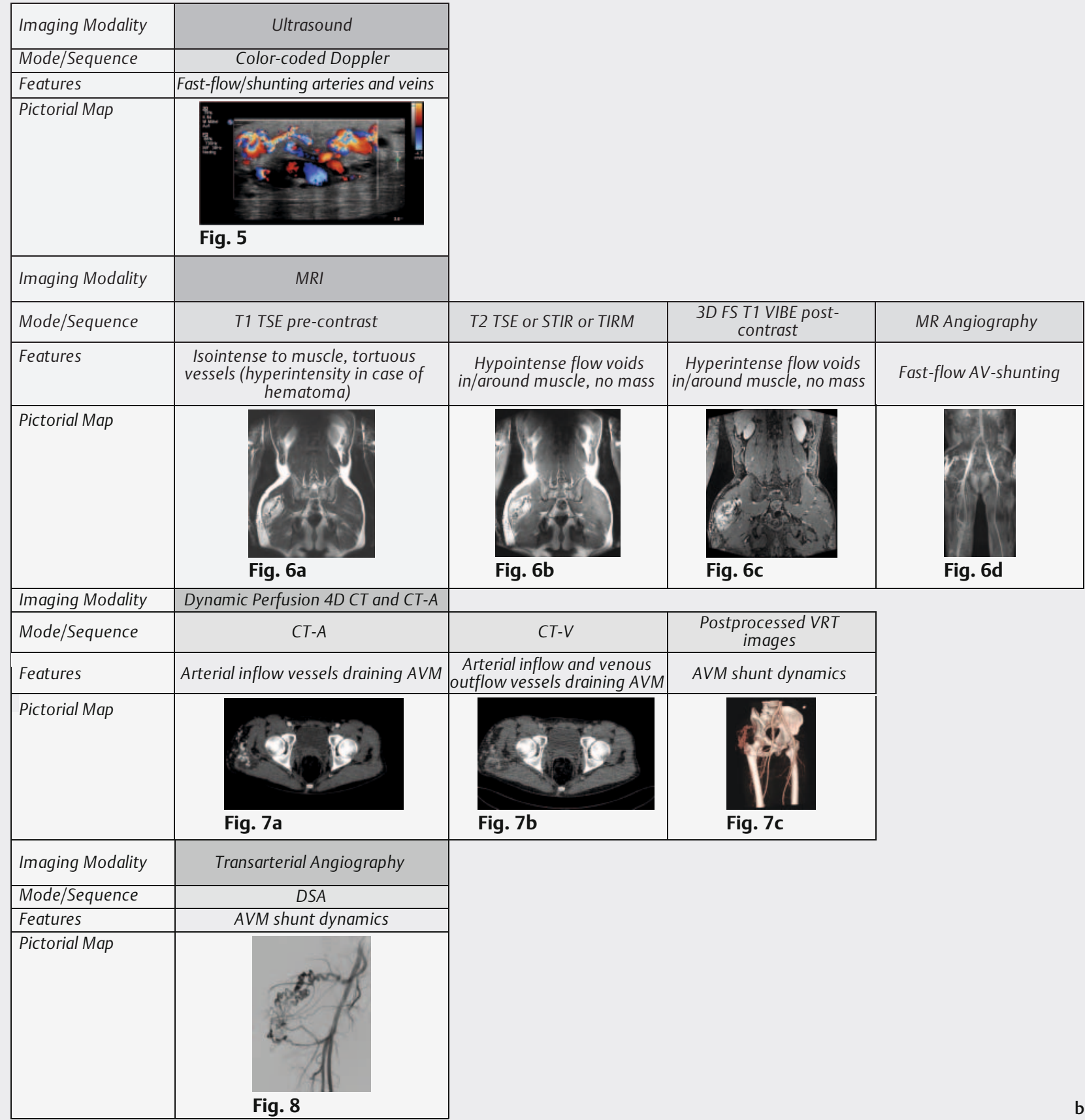

- Fig. 1 a-c Features of Peripheral Vascular Anomalies on Dedicated Imaging with Pictorial Overview. b Fast-Flow Arterio-Venous Malformations (Vascular Anomaly).

- Abb. 1 a-c Merkmale peripherer Gefäßanomalien anhand dedizierter Bildgebung und Bildbeispielen. b Fast-flow-arteriovenöse Malformationen (Gefäßanomalie). 
FAST-FLOW Hemangiomas (Vascular Tumor)
FAST-FLOW Hämangiome (Gefäßtumor)

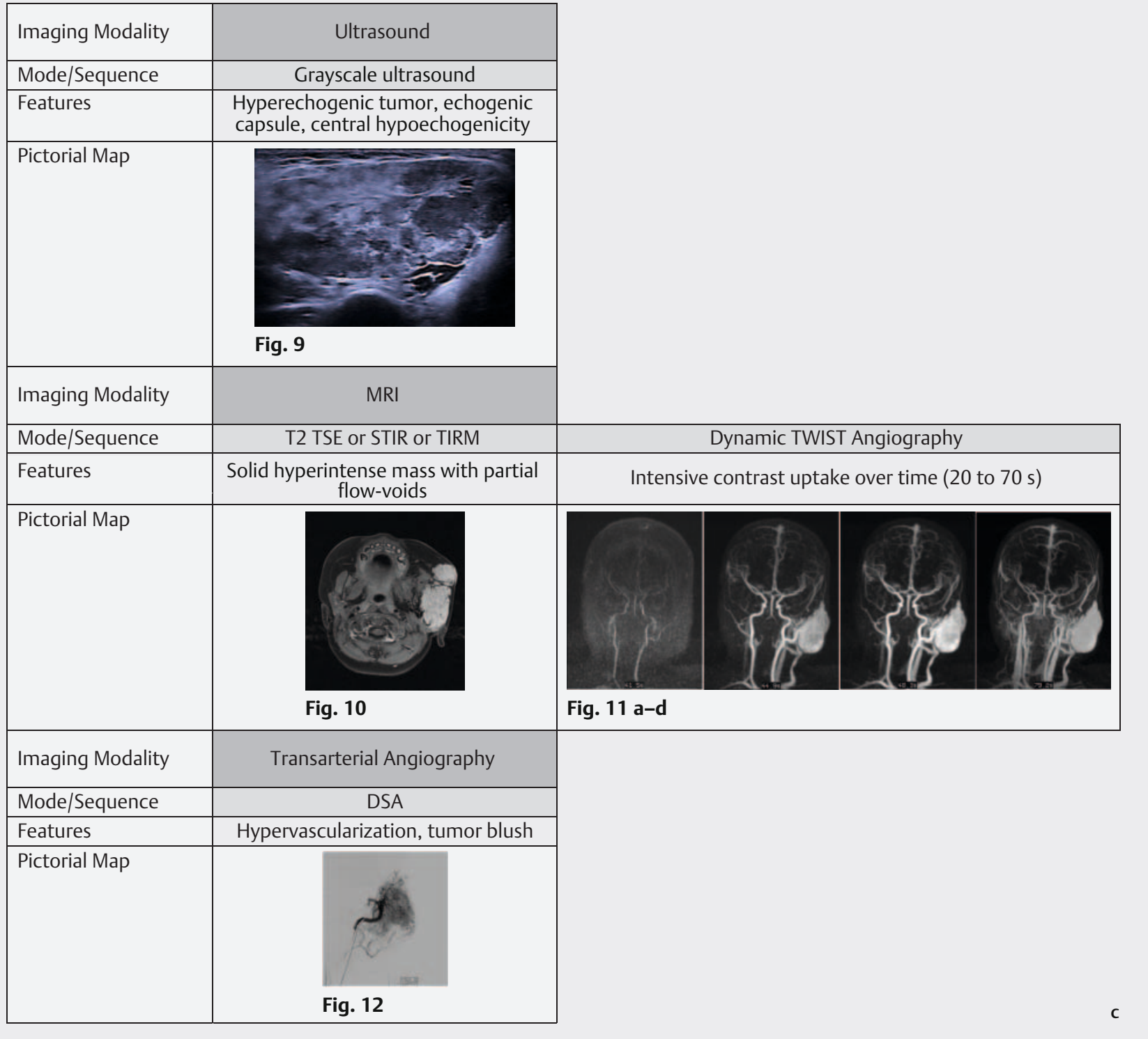

- Fig. 1 a-c Features of Peripheral Vascular Anomalies on Dedicated Imaging with Pictorial Overview. c Fast-Flow Hemangiomas (Vascular Tumor).

- Abb. 1 a-c Merkmale peripherer Gefäßanomalien anhand dedizierter Bildgebung und Bildbeispielen. c Fast-Flow-Hämangiome (Gefäßtumor).

arterial flow on color-coded ultrasound. If not involuted, they may be distinguished at subcutaneous or deep tissue levels. In large hemangiomas, especially in the head and neck region, ultrasound is usually combined with MR cross-sectional imaging for further evaluation of neighboring vital structures, like the upper aerodigestive tract and the cervical vessels $[15,16]$.

AVMs demonstrate high-velocity arterio-venous shunting on ultrasound that cannot be solely depicted on grayscale images, especially when extensive in size. Ultrasound and color-coded duplex sonography are mandatory for intraprocedural monitoring of percutaneous embolization procedures in AVMs [17, 18].
Representing a dynamic imaging tool with good availability, ultrasound is essential in AVMs that have to be accessed percutaneously for embolization. The depth and extension of the AVM nidus as well as needle guidance into inflow and outflow vessels can be depicted. Besides intraprocedural monitoring, immediate postprocedural assessment of the degree of embolization may be obtained.

Despite their morphological diversity, slow-flow venous malformations appear as hypoechogenic clusters of grape-shaped or tubular channels, which are very compressible on grayscale ultrasound. Calcified hyperechogenic phleboliths may be visible 


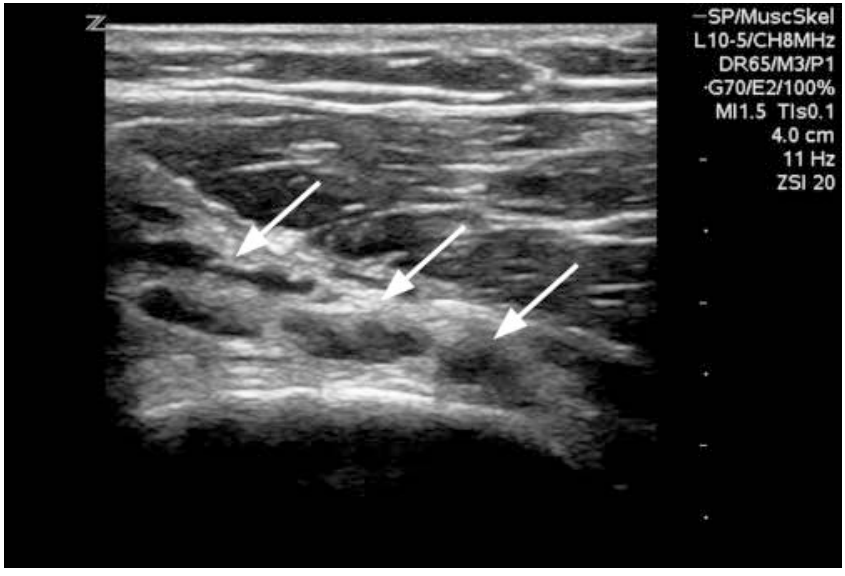

- Fig. 2 Intramuscular venous malformation in the left lower extremity. On grayscale ultrasound, echopoor intramuscular clusters in the quadriceps muscle, adjacent to the distal femoral bone (see arrows), are visible.

- Abb. 2 Intramuskuläre venöse Malformation in der linken unteren Extremität. Echoarme intramuskuläre Cluster im Ultraschall im M. quadriceps femoris, angrenzend an den Femurschaft (siehe Pfeile). in the case of post-inflammatory changes [19]. Grayscale imaging should be used routinely for the assessment of location, spread and size of slow-flow vascular anomalies.

\section{Magnetic Resonance Imaging}

Contrast-enhanced magnetic resonance imaging (MRI) is an established diagnostic modality for the assessment of slow-flow and fast-flow vascular anomalies, involving not only superficial anatomical structures, but also deep tissue layers of muscle, inner organs and bone $[20,21]$. Syndromal vascular anomalies are frequently associated with limb and soft tissue hypertrophia which can be well delineated on MRI, too. Prolonged imaging time has to be considered in extensive vascular anomalies for complete evaluation, including MR-venography.

Time-resolved 3D MRA with high spatial and temporal resolution, such as TWIST MR-angiography (time-resolved angiography with interleaved stochastic trajectories), is essential for the analysis of fast-flow vascular anomalies [22]. During the passage of contrast agent, hemangiomas and AVMs with multiple arterial inflow feeder and outflow draining veins can be effectively depicted.

The MRI protocols for fast-flow and slow-flow vascular anomalies should include standard MR sequences like T1-weighted
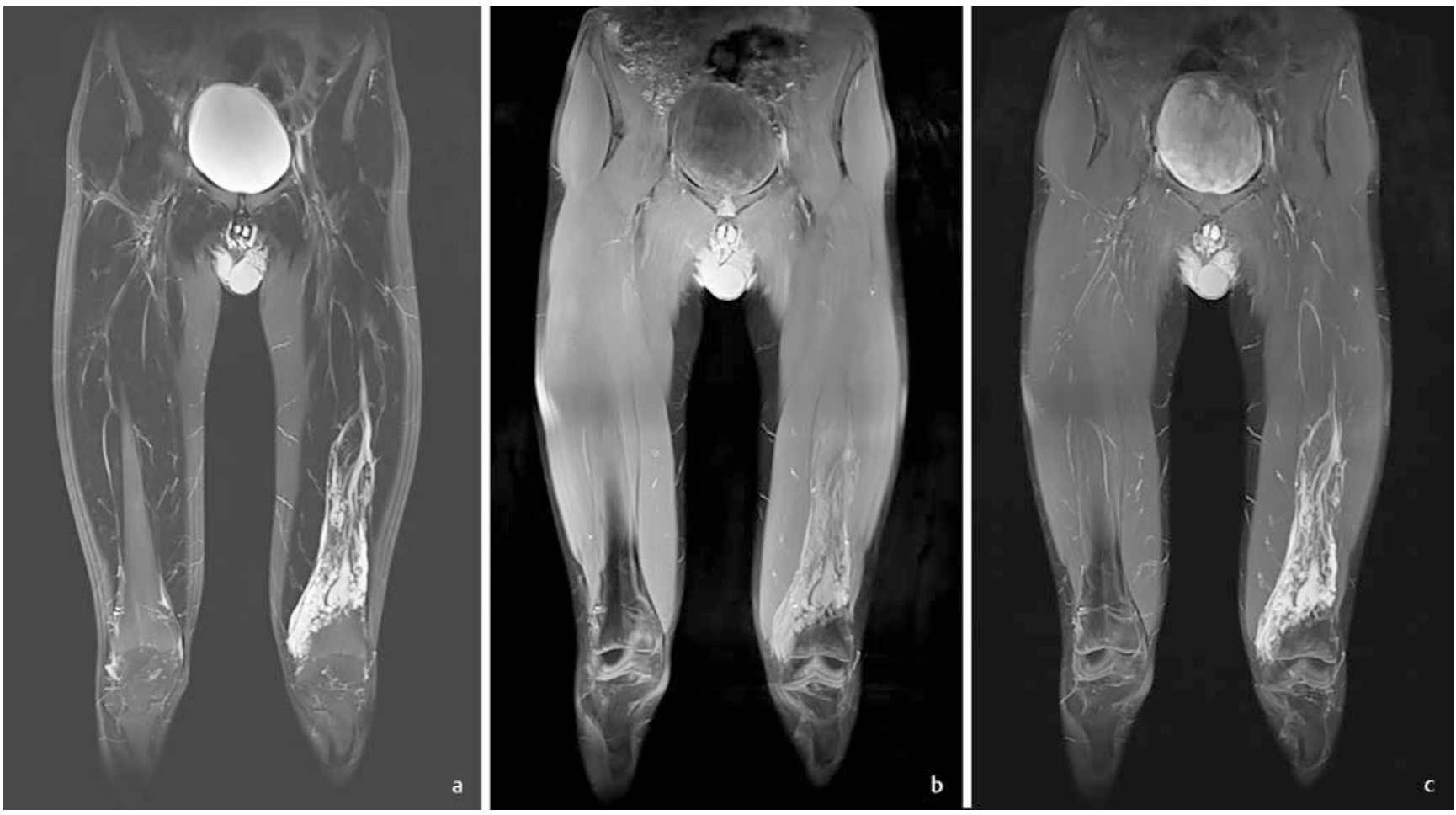

- Fig. 3 Intramuscular venous malformation on MRI in the left lower quadriceps muscle, adjacent to the femoral bone. a TIRM coronal image, hyperintense venous clusters adjacent to muscles and bone. $\mathbf{b}$ T1 TSE pre-contrast coronal image, isointense venous clusters adjacent to muscles and bone. c 3 D FS T1 VIBE post-contrast coronal image, hyperintense venous clusters adjacent to muscles and bone.

- Abb. 3 Intramuskuläre venöse Malformation in der linken unteren Extremität, angrenzend an den Femurschaft, im MRT. a TIRM koronar, hyperintense venöse Cluster angrenzend an Muskel und Knochen. b T1-TSE koronar vor Kontrastmittel, isointense venöse Cluster angrenzend an Muskel und Knochen. c 3D-FS-T1-VIBE koronar nach Kontrastmittel, hyperintense venöse Cluster angrenzend an Muskel und Knochen. 


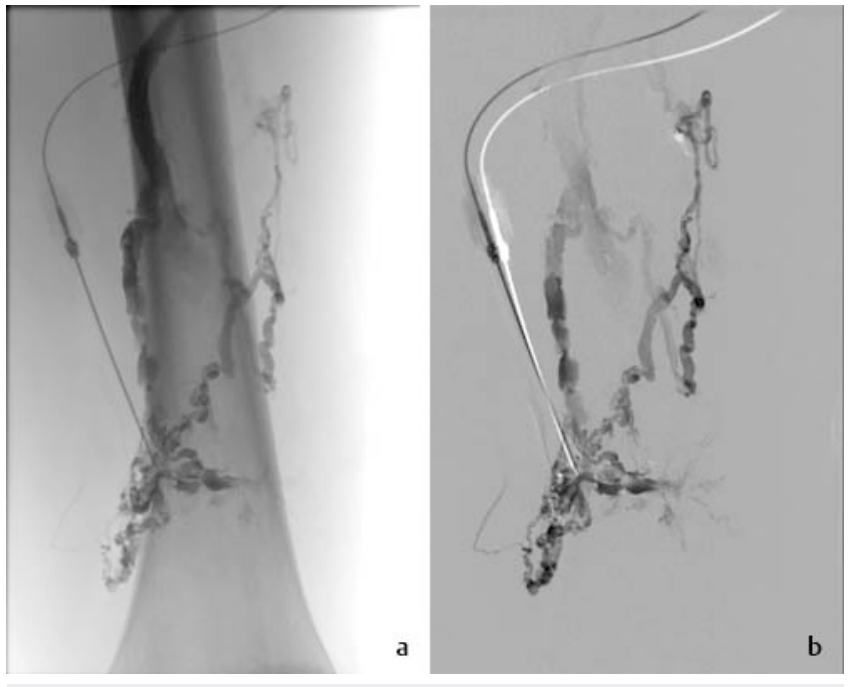

- Fig. 4 a Intramuscular venous malformation on conventional percutaneous phlebography in the left lower quadriceps muscle without DSA. b Intramuscular venous malformation on conventional percutaneous phlebography in the left lower quadriceps muscle with DSA.

- Abb. 4 a Intramuskuläre venöse Malformation in der linken unteren Extremität in der konventionellen Phlebografie ohne DSA. b Intramuskuläre venöse Malformation in der linken unteren Extremität in der konventionellen Phlebografie mit DSA.
TurboSpinEcho sequences pre- and post-contrast (T1 TSE), T2-weighted TurboSpinEcho sequences (T2 TSE) and timeresolved 3D MR-angiography with high spatial and temporal resolution. Fat suppression imaging with turbo inversion recovery magnitude (TIRM) or T1 inversion recovery sequences (STIR) should be applied initially for overall screening of the underlying vascular anomaly.

A fast-flow MR imaging protocol for vascular anomalies should combine multiplanar T1 TSE sequences, multiplanar T2 TSE sequences, time-resolved $3 \mathrm{D}$ MR-angiography and early postcontrast T1-weighted fat-saturated sequences (for example, $3 \mathrm{D}$ volumetric interpolated breath-hold sequences, T1vibe fs 3D).

A dedicated slow-flow MR imaging protocol for venous malformations should include multiplanar fat-suppressed TIRM or STIR sequences for overall screening, T1 TSE sequences pre- and postcontrast and T2 TSE sequences. Late post-contrast T1-weighted fat-saturated sequences are important to depict contrast material pooling in venous malformations in order to differentiate between vital and thrombosed areas in the vascular anomaly. Yet, awareness has to be created for the importance of prolonged steady-state imaging in the venous phase as it demonstrates perfusion of venous malformations [6, 7, 15, 22-24]. MR-venography should be performed for analysis of the deep venous system of the affected limb and potential thrombotic displacement of the lumen. - Fig.1-12 summarizes dedicated fast-flow and slowflow vascular anomalies, including their MRI protocols and the individual imaging appearance of the vascular anomaly in each recommended MR sequence.

\section{Computed Tomography}

The possibility of perfusion $C T$ imaging in arterial (CT-A) and venous (CT-V) phase on new generation CT scanners (for example, SOMATOM Force Dual-Source CT Scanner, Siemens Healthineers) allows time-resolved CT-angiography and CT-venography (4D CTA and (TV) over a wide z-axis coverage in combination with low tube voltage settings down to $70 \mathrm{kVp}[25,26]$. Fast and motion artifact-free imaging is combined with reduced iodine contrast injection and less radiation exposure. Especially young and disabled patients may benefit from these parameters [27].

Perfusion 4D CT imaging is not recommended as a standard imaging tool, especially in slow-flow vascular anomalies. Perfusion analysis of arterial feeding vessels and venous drainage of complex AVMs requires repetitive imaging with increased radiation exposure, which has to be taken into consideration [28]. In highly complex and extensive fast-flow AVMs, 4D CT imaging should be reserved for intervention planning, when arterial inflow vessels to the nidus of the AVM and venous outflow have to be identified for transarterial, transvenous and percutaneous access to the lesion during one embolization procedure [29]. Intervention time and associated radiation exposure during DSA can be reduced and the selection of catheter devices facilitated, when axial perfusion images and postprocessed reformatted CT images in $4 \mathrm{D}$ or $3 \mathrm{D}$ view in dynamic volume rendering technique display the rich arteriovenous shunting in fast-flow vascular anomalies well [30].

\section{Catheter Angiography}

Invasive catheter angiography is the prerequisite before embolization of fast-flow vascular anomalies like hemangiomas and AVMs. Full depiction of arteriovenous shunting, nidus and venous outflow is obtained prior to embolotherapy. Angiography may be performed catheter-based via the transarterial or transvenous route or percutaneously by ultrasound-guided direct puncture of the AVM [31]. Invasive catheter angiography has no significance in the diagnosis and treatment of slow-flow vascular anomalies.

\section{Direct Percutaneous Phlebography}

In slow-flow vascular anomalies like venous malformations, direct percutaneous phlebography offers appropriate information on the location, extension and patency of the vascular anomaly prior to sclerotherapy [32]. Assessment of venous drainage status according to the Puig Classification facilitates treatment planning with regard to the need for intraprocedural compression or tourniquet to prevent non-target sclerotherapy.

\section{Features of Peripheral Vascular Anomalies on Dedicated Imaging}

This paragraph gives an overview on the features of slow-flow vascular anomalies like venous malformations, followed by the characteristics of fast-flow vascular anomalies like AVMs and fast-flow vascular tumors like hemangiomas. The imaging characteristics are described and accompanied by representative diagnostic figures of the vascular anomalies. 


\section{Venous Malformations}

Venous malformations (VMs) represent the most frequent lowflow vascular anomaly $[6,32]$. They occasionally include calcifications after recurrent thrombophlebitis which can be easily diagnosed as phleboliths on conventional X-ray. In the pelvic region, a possible differential diagnosis of phleboliths may be the presence of ureteric calculus. Ultrasound can help to identify a venous malformation versus calcifications in the urinary tract.

On ultrasound, venous malformations appear as hypoechogenic, rarely thrombosed hyperechogenic clusters of malformed

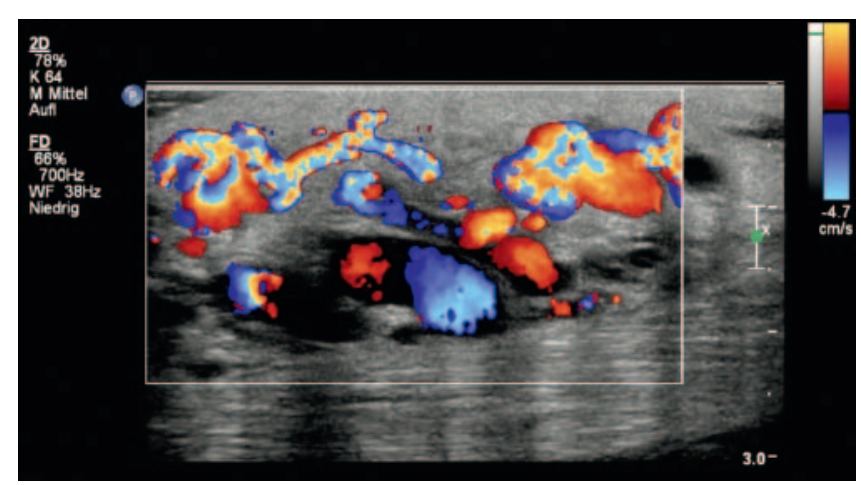

- Fig. 5 Intramuscular arteriovenous malformation in the right gluteal muscle on color-coded Doppler with clusters of several dilated inflow and outflow vessels.

- Abb.5 Intramuskuläre arteriovenöse Malformation in der rechten Glutealloge. Im Farbdoppler Nachweis zahlreicher Gefäßnester mit dilatierten Inflow- und Outflow-Gefäßen. nodular or tubular veins. Color-coded Duplex sonography will demonstrate a typical no-flow pattern.

MRI is the imaging method of choice for venous malformations. The MRI protocol for slow-flow vascular anomalies like VMs should include standard MR sequences like T1 TSE, T2 TSE and time-resolved $3 \mathrm{D}$ MR-angiography with high spatial and temporal resolution. Fat suppression imaging with TIRM or STIR sequences should be applied as an initial overall screening mode for the underlying vascular anomaly [33].

It is important to attain late post-contrast T1-weighted images (for example, fat-saturated 3 D volumetric interpolated breathhold sequences, T1 vibe fs 3D) in order to detect non-thrombosed active parts of a venous malformation. MR-venography on late post-contrast $\mathrm{T1}$-weighted images is also required for overall assessment of the deep draining veins.

Conventional percutaneous phlebography demonstrates clusters of malformed veins with contrast pooling but no signs of arterio-venous shunting. For treatment planning, the classification of venous malformations according to the Puig classification is important [32]. Type I VMs are isolated and do not drain into surrounding veins, type II VMs drain into non-dilated normal veins whereas type III VMs drain into dilated and type IV VMs into dysplastic veins. In type III and IV VMs, sclerotherapy has to be monitored closely because of the risk of non-target sclerotherapy of adjacent veins with local thrombosis or pulmonary embolism.

\section{Arterio-Venous Malformations}

AVMs appear as fast-flow shunting malformations on ultrasound and color-coded Duplex sonography. Clusters of dilated arteries
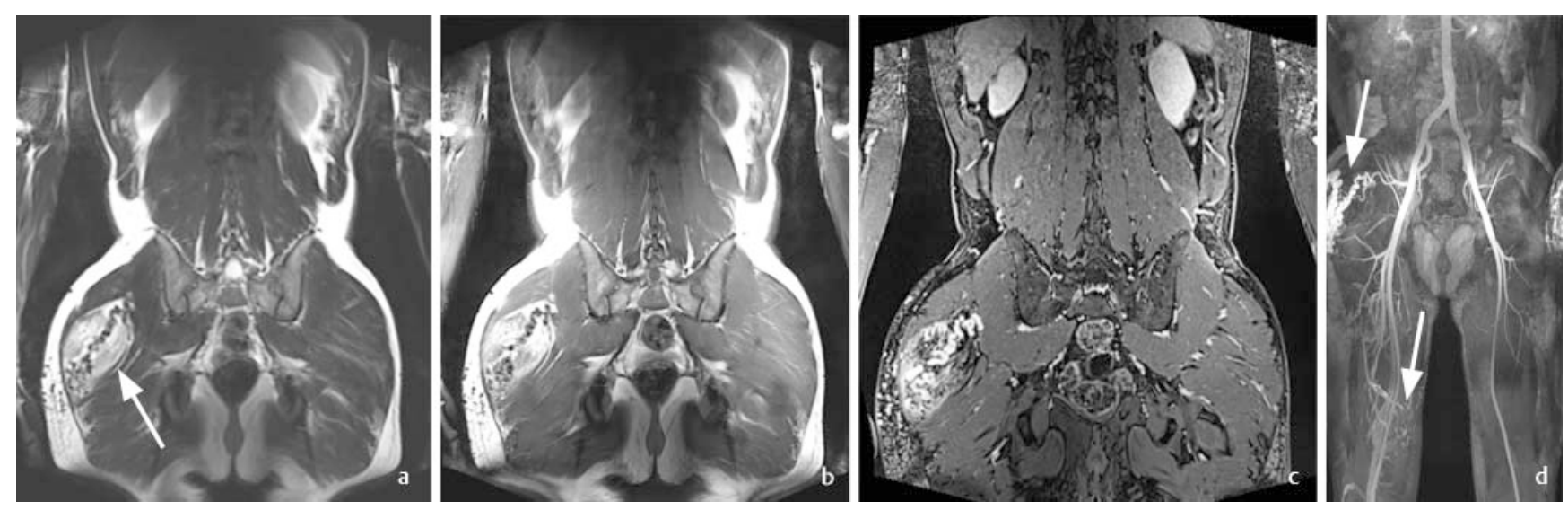

- Fig. 6 a-d MRI appearance of an intramuscular arteriovenous malformation in the right gluteal fossa with adjacent intramuscular bruising. a T2 TSE image, AVM with many tortuous vessels isointense to muscle, no mass around prominent flow voids, hyperintensity induced by muscle bruising (see arrow) around the AVM. b T1 TSE pre-contrast image, AVM with many tortuous vessels hypointense to muscle. c 3 D FS T1 VIBE post-contrast image, AVM with many tortuous vessels hyperintense to muscle, no solid mass around the AVM. $\mathbf{d}$ MR-TWIST Angiography, fast-flow AV-shunts in the right gluteal fossa and the right lower limb (see arrows).

- Abb.6 a-d MRT einer intramuskulären arteriovenösen Malformation in der rechten Glutealloge mit angrenzendem Muskelhämatom. a T2-TSESequenz, AVM mit zahlreichen torquierten Gefäßen, isointens zu Muskelgewebe, keine Raumforderung um die prominenten Flow-voids, Hyperintensität verursacht durch Muskelhämatom um die AVM (siehe Pfeil). b T1-TSE-Sequenz vor Kontrastmittel, AVM mit zahlreichen torquierten Gefäßen, hypointens zu Muskelgewebe. c 3D-FS-T1-VIBE nach Kontrastmittel, AVM mit zahlreichen torquierten Gefäßen, hyperintens zu Muskelgewebe, keine solide Raumforderung um die AVM. d MR-TWIST-Angiografie, Fast-flow-AV-shunts in der rechten Glutealloge und der rechten unteren Extremität (siehe Pfeile). 

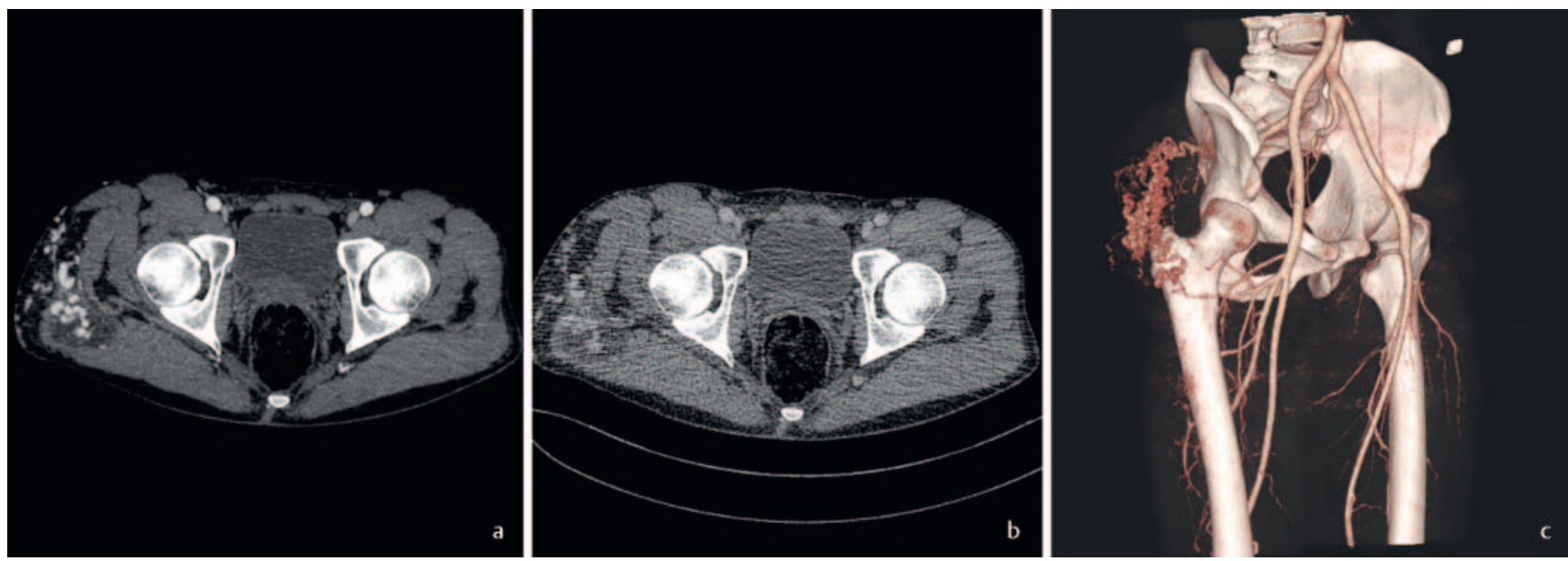

- Fig. 7 a-c CT appearance of an intramuscular arteriovenous malformation in the right gluteal fossa with adjacent intramuscular bruising. a CT-A, AVM with many tortuous intramuscular and subcutaneous arterial vessels. b CT-V, AVM with many tortuous intramuscular and subcutaneous arterial and venous draining vessels. c VRT of AVM shunt dynamics.

- Abb.7 a-c CT einer intramuskulären arteriovenösen Malformation in der rechten Glutealloge mit angrenzendem Muskelhämatom. a CT-A, AVM mit zahlreichen torquierten Gefäßen und subkutanen arteriellen Feedern. b CT-V, AVM mit zahlreichen torquierten Gefäßen und subkutanen arteriellen und venösen Feedern. c VRT der AVM-shunt-Dynamik.

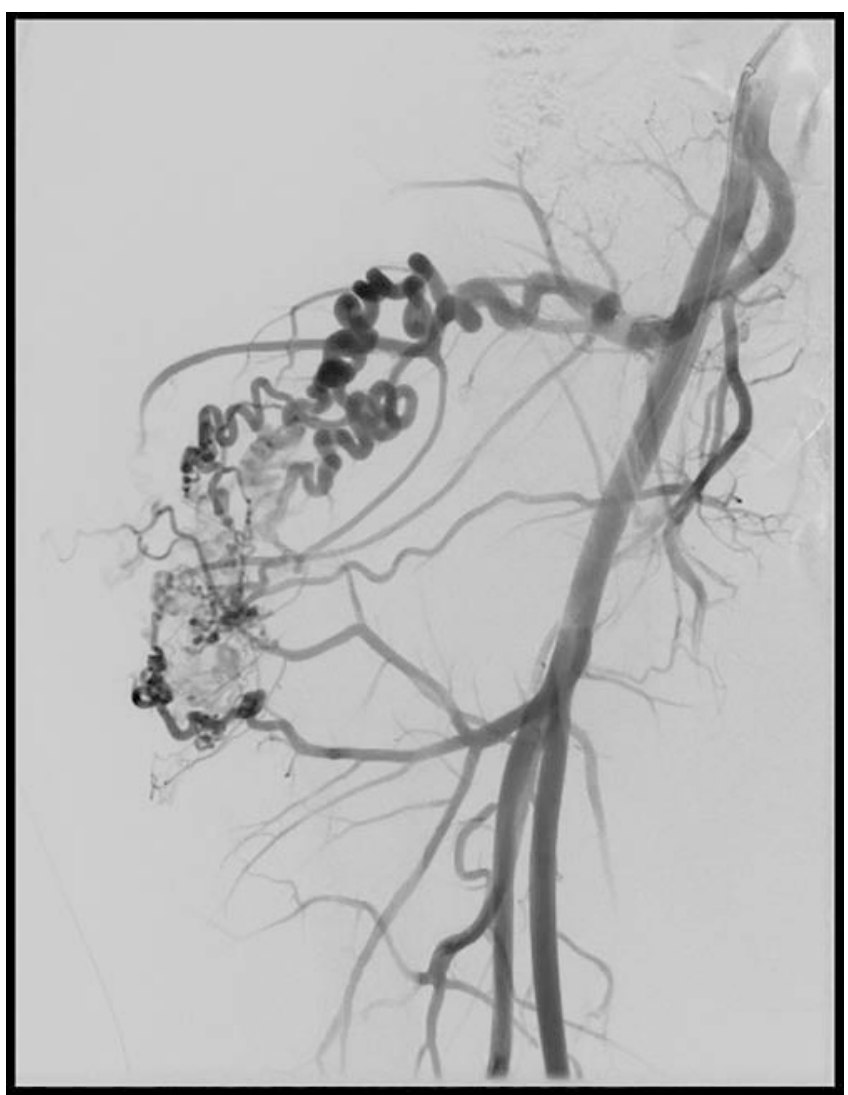

- Fig. 8 Catheter angiography of the intramuscular fast-flow arteriovenous malformation in the right gluteal fossa before embolization.

- Abb. 8 Katheterangiografie der intramuskulären arteriovenösen Malformation in der rechten Glutealloge vor Embolisation. and veins drain into a nidus with several arterial inflow and venous outflow vessels.

The fast-flow characteristics of AVMs are well displayed on MR TWIST angiography (time-resolved angiography with interleaved stochastic trajectories) and post-contrast T1-weighted fat-saturated $3 \mathrm{D}$ volumetric interpolated breath-hold sequences [34]. AVMs are never composed of a solid, well-defined mass on MRI. On T2-weighted TurboSpinEcho (T2 TSE) sequences and pre-contrast T1-weighted TSE images, AVMs resemble a sack of worms with multiple hypointense tortuous flow voids.

Time-resolved 4D-CT-angiography (4 D CTA) has recently become an integral part of complex therapy planning. It has replaced catheter angiography in the diagnostic evaluation of extensive AVMs with multiple arterial inflow vessels to the nidus and several dominant outflow veins. With the possibility of an extensive scan field, perfusion dynamics of an entire limb affected by an AVM, can be analyzed. Besides, post-processed images offer valuable information for the embolization procedure as far as access to the AVM, choice of embolic agent and catheter devices are concerned ( $\vee$ Table 1$)[5-7,10]$.

DSA images during catheter angiography guide the interventionalist in the case of transarterial and/or transvenous embolization of the AVM, which may also be performed by direct percutaneous puncture $[7,31]$.

\section{Hemangiomas}

The most common benign representative of vascular tumors are hemangiomas. Unless thrombosed, they are fast-flow lesions that have characteristic imaging features $[6,7,14]$.

On ultrasound, hemangiomas usually appear as a solid echogenic mass, densely packed with vessels and prominent highvelocity arterial flow on color-coded duplex sonography $[4,10]$. 


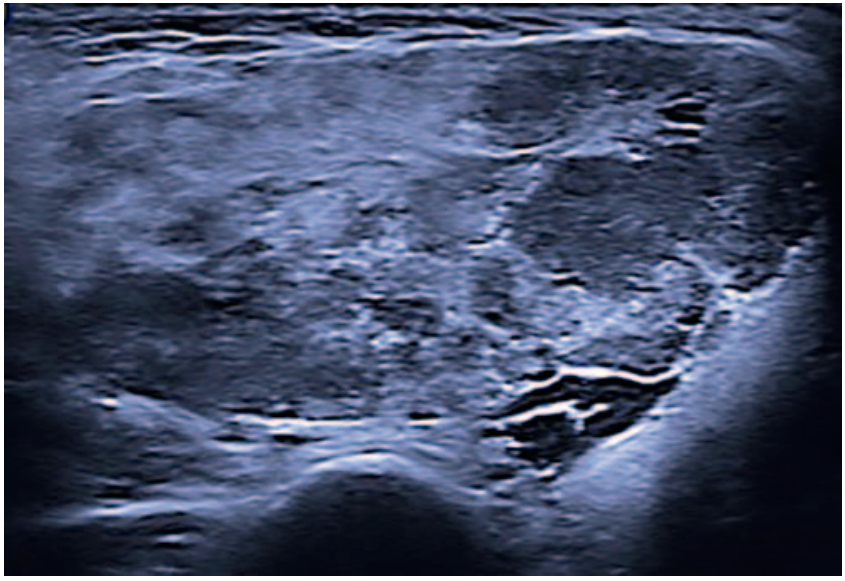

- Fig. 9 Infantile hemangioma in the left masseter muscle. Grayscale ultrasound demonstrates a hyperechogenic tumor surrounded by a thin echogenic capsule. The hemangioma partially includes hypoechogenic central areas.

- Abb.9 Infantiles Hämangiom in der linken Masseterloge. Im Ultraschall Nachweis eines echovermehrten Tumors mit echogener Kapselstruktur. Das Hämangiom zeigt vereinzelt echoverminderte zentrale Anteile.

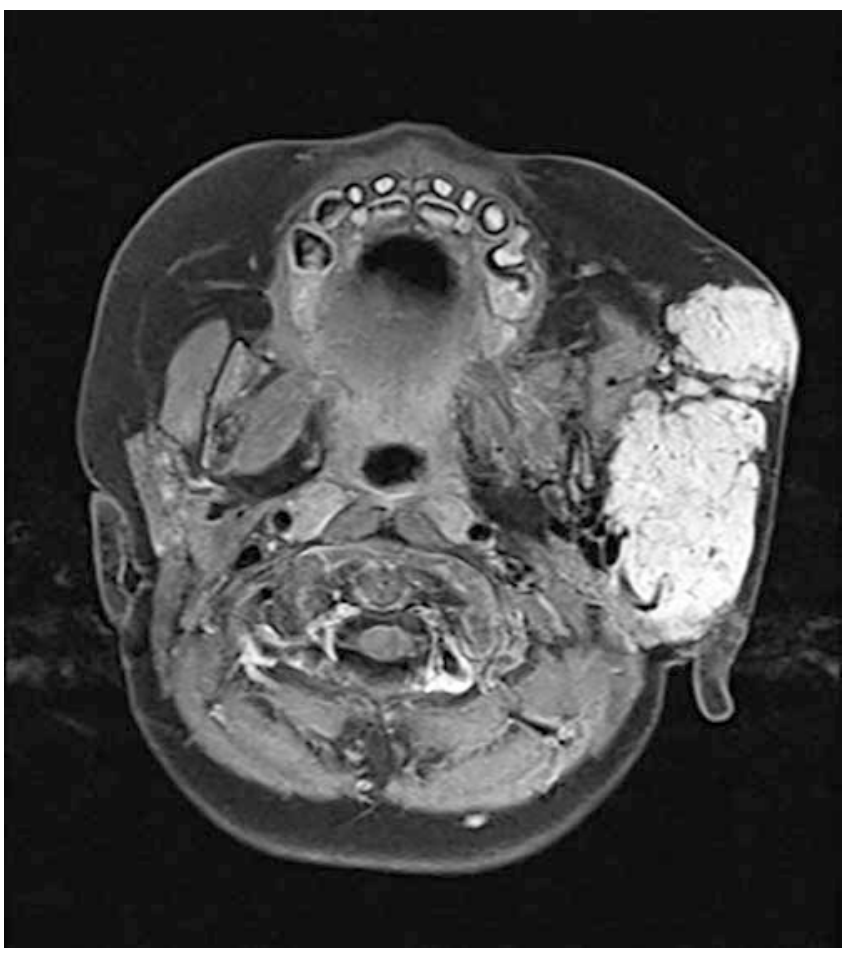

- Fig. 10 Infantile hemangioma in the left masseter muscle. The T2 TSE sequence demonstrates a solid hyperintense tumor with flow voids.

- Abb.10 Infantiles Hämangiom in der linken Masseterloge. In der T2 TSE Sequenz imponiert ein solider hyperintenser Tumor, durchsetzt von Flow-voids.
In the case of extensive deep tissue hemangiomas, MRI evaluates the size and location as well as adjacent anatomical structures. In non-contrast T1 TSE images, hemangiomas are hypointense and turn hyperintense on post-contrast T1 TSE images with multiple flow voids due to their vascularization. TWIST angiography depicts the vascularity of hemangiomas. They rarely require interventional therapy. In that case catheter angiography displays the arterial blush of these well-vascularized tumors prior to selective embolization.

\section{Conclusion}

Vascular anomalies are a rare disease and present a diagnostic challenge. Knowledge of the clinical phenotypes of vascular anomalies along with their individual flow dynamics is necessary to select appropriate imaging tools. The differentiation between slow-flow and fast-flow malformations and tumors is fundamental to confirm diagnosis and to plan and optimize treatment $[5,6,14$, 31].

This overview describes the entire spectrum of currently established imaging modalities available for peripheral vascular anomalies, ranging from conventional X-ray to cross-sectional imaging and invasive procedures like phlebography and catheter angiography. For the purpose of visualization, imaging features of peripheral vascular anomalies are highlighted with pictorial maps.

When selecting imaging modalities, one should initially always consider radiation-free techniques for the diagnostic assessment of vascular anomalies, especially in infants and young patients. Another point of consideration is the aim of imaging, which can be either baseline assessment, follow-up or strategic planning of an interventional procedure. Complex vascular anomalies, especially fast-flow AVMs, may require additional dedicated perfusion analysis with 4D CT imaging for treatment planning. Radiation exposure remains a challenge in the treatment of complex AVMs and always demands strict risk-benefit stratification for each patient.

Publications on noninvasive imaging techniques for the measurement of tissue perfusion, besides MRI, have lots of potential as dynamic quantitative assessment tools, but need to be investigated further in the context of vascular anomalies [35]. Masthoff et al. have described the use of multispectral optoacoustic tomography for the diagnosis of vascular malformations and differentiation between pre- and post-therapeutic outcome in venous malformations and AVMs [36]. Image acquisition at 700 to $850 \mathrm{~nm}$ and a laser penetration depth of $3 \mathrm{~cm}$ are promising steps for dynamic functional imaging of vascular anomalies, especially with respect to bedside examination and its noninvasiveness. Yet, the method is in a fledgling stage and not available as a comprehensive imaging tool for vascular anomalies.

The goal of this review is to simplify the diagnostic approach to vascular anomalies and to facilitate the choice of the most appropriate imaging tool among current and emerging standards of radiological diagnostic workup for congenital vascular anomalies. 

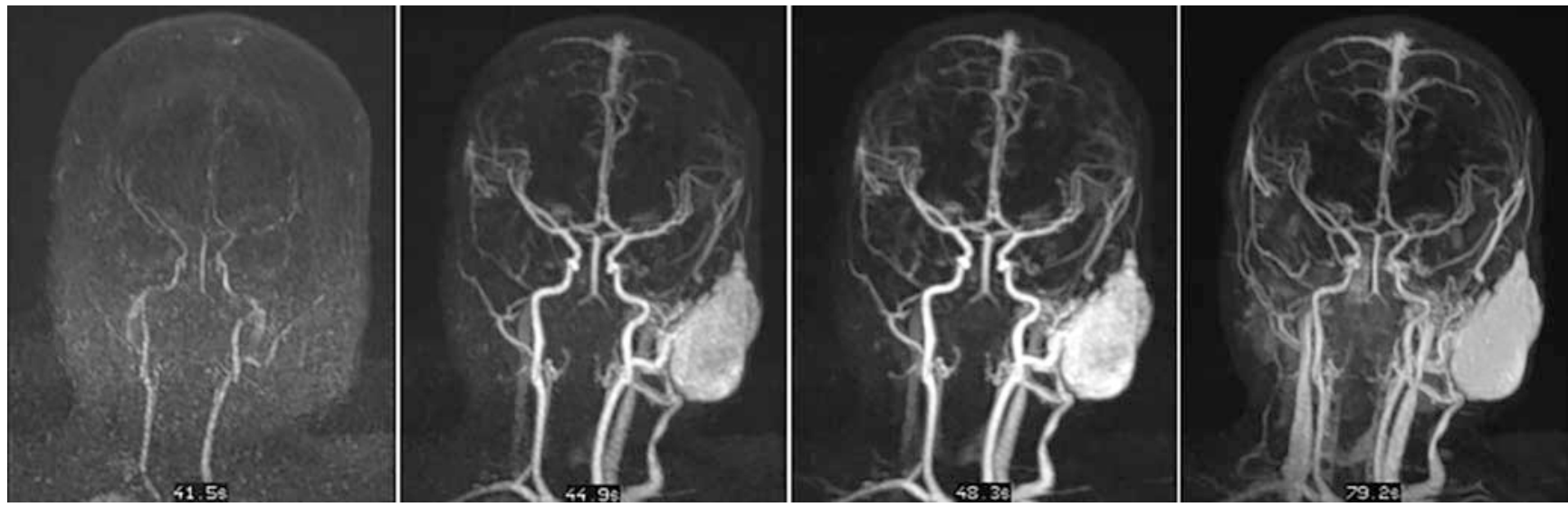

- Fig. 11 a-d Infantile hemangioma in the left masseter muscle. TWIST MR-Angiography shows intensive contrast uptake in the hemangioma over time (20 s until 70 s).

- Abb.11 Infantiles Hämangiom in der linken Masseterloge. Die TWIST-MR-Angiografie demonstriert die intensive Kontrastmittelaufnahme über die Zeit (20 bis 70 Sekunden).

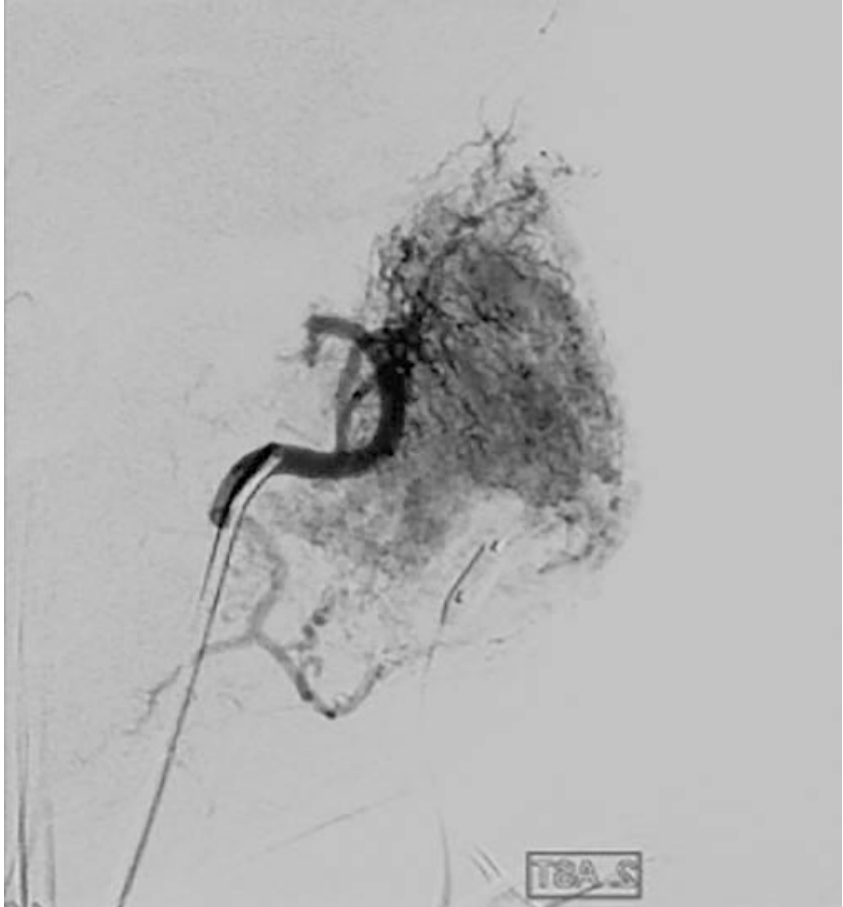

Fig. 12 Catheter angiography of the intramuscular infantile hemangioma in the left masseter muscle demonstrating hypervascularization.

- Abb. 12 Katheterangiografie des hypervaskularisierten intramuskulären infantilen Hämangioms in der linken Masseterloge.

\section{Conflict of Interest}

The authors declare that they have no conflict of interest.

\section{Literatur}

[1] Nassiri N, Cirillo-Penn NC, Thomas J. Evaluation and management of congenital peripheral arteriovenous malformations. J Vasc Surg 2015; 62: 1667-1676

[2] Frey S, Haine A, Krammer R et al. Hemodynamic Characterization of Peripheral Arterio-venous Malformations. Annals of Biomed Eng 2017; 45: $1449-1461$

[3] Tahir M, Mumtaz MA, Sultan A et al. Role of Interventional Radiology in the Management of Peripheral Vascular Malformations: A Tertiary Care Center Experience. Cureus 2018; 10: e2325. doi:10.7759/cureus.2335

[4] Mulliken JB, Glowacki J. Hemangiomas and Vascular Malformations in Infants and Children: a classification based on endothelial characteristics. Plast Reconstr Surg 1982; 69: 412-422

[5] Wassef M, Blei F, Adams D et al. Vascular Anomalies Classification: Recommendations From the International Society for the Study of Vascular Anomalies. Pediatrics 2015; 136: e203-e214

[6] Sadick M, Müller-Wille R, Wildgruber M et al. Vascular Anomalies (Part I): Classification and Diagnostics of Vascular Anomalies. Rofo 2018; 190 : 825-835

[7] Müller-Wille R, Wildgruber M, Sadick M et al. Vascular Anomalies (Part II): Interventional Therapy of Peripheral Vascular Malformations. Rofo 2018. doi:10.1055/s-0044-101266

[8] Gorman J, Zbarsky SJ, Courtemanche RJM et al. Image guided sclerotherapy for the treatment of venous malformations. CVIR Endovasc 2018. doi:10.1186/s42155-018-0009-1

[9] Sadick M, Dally F], Schönberg SO et al. Strategies in Interventional Radiology: Formation of an Interdisciplinary Center of Vascular Anomalies Chances and Challenges for Effective and Efficient Patient Management. Röfo 2017; 189: 957-966

[10] http://www.diggefa.de - letzter Zugriff 01.06.2019

[11] Wojcicki P, Wojcicka K. Epidemiology, Diagnostics and Treatment of Vascular Tumors and Malformations. Adv Clin Exp Med 2014; 23: 475-484

[12] Ten Broek RW, Eijkelenboom A, van der Vleuten CJM et al. Comprehensive molecular and clinicopathological analysis of vascular malformations: A study of 319 cases. Genes Chromosomes Cancer 2019. doi:10.1002/gcc.22739 
[13] Gilbert P, Dubois ], Giroux MF et al. New Treatment Approaches to Arteriovenous Malformations. Semin Intervent Radiol 2017; 34: 258-271

[14] Wildgruber M, Sadick M, Müller-Wille R et al. Vascular tumors in infants and adolescents. Insights Imaging 2019. doi:10.1186/s13244-0190718-6

[15] Majewska NK, Stajgis P, Wykretowicz M et al. Peripheral vascular malformations - modern imaging. Pol J Radiol 2018; 83: 253-259

[16] Rusu GM, Ciuce C, Fodor L et al. Ultrasonographic and imaging appearance of peripheral intraneural vascular anomalies: report of two cases and review of the literature. Med Ultrason 2018; 20: 237-246

[17] Mennitt K, Deol M, Gao J. Emergency color Doppler sonography of the extremity artery: A pictorial essay. Clinical Imaging 2017; 42: 240-248

[18] Esposito F, Ferrara D, Di Serafino M et al. Classification and ultrasound findings of vascular anomalies in pediatric age: the essential. Journal of Ultrasound 2018. doi:10.1007/s40477-018-0342-1

[19] Johnson AB, Richter GT. Vascular Anomalies. Clin Perinatol 2018; 45: 737-749

[20] Prasad NK, Chawla A, Lalezari S et al. A radiological classification system for intraneural vascular anomalies: assessment of potential for resection with high-resolution MRI. Acta Neurochir 2016; 158: 329-334

[21] Schicchi N, Tagliati C, Agliata G et al. MRI evaluation of peripheral vascular anomalies using time-resolved imaging of contrast kinetics (TRICKS) sequence. La radiologia medica 2018; 123: 563-571

[22] https://www.healthcare.siemens.de/magnetic-resonance-imagi ng/clinical-specialities/body-mri/highlights - letzter Zugriff 01. Juni 2019

[23] Hammer S, Uller W, Manger F et al. Time-resolved magnetic resonance angiography (MRA) at 3.0 Tesla for evaluation of hemodynamic characteristics of vascular malformations: description of distinct subgroups. Eur Radiol 2017; 27: 296-305

[24] MacDonald ME, Dolati P, Mitha AP et al. Flow and pressure measurements in aneurysms and arteriovenous malformations with phase contrast MR imaging. Magn Reson Imaging 2016; 34: 1322-1328

[25] Benzar I. A Diagnostic Program of Vascular Tumor and Vascular Malformations in Children According to Modern Classification. Acta Medica 2017; 60: 19-26

[26] Henzler T, Vogler N, Lange B et al. Low dose time-resolved CT-angiography in pediatric patients with venous malformations using 3rd generation dual-source CT: Initial experience. Eur J Radiol Open 2016; 12: $216-222$

[27] Tekes A, Kalayci TO, Mitchell SE. Congenital Vascular Anomalies: Classification and Terminology. In: Mauro MA, Murphy KP, Thomson KR, (eds) Image Guided Interventions. Philadelphia: Saunders; 2013: 271-283

[28] Wildgruber M, Köhler M, Brill R et al. Impact of low dose settings on radiation exposure during pediatric fluoroscopic guided interventions. Eur J Radiol 2018; 100: 1-6

[29] Muehlen I, Kloska SP, Gölitz P et al. Noninvasive Collateral Flow Velocity Imaging in Acute Ischemic Stroke: Intraindividual Comparison of 4D-CT Angiography with Digital Subtraction Angiography. Röfo 2019. doi:10.1055/a-0825-6660

[30] Albrecht MH, Vogl T], Wichmann JL et al. Dynamic 4D-CT Angiography for Guiding Transarterial Chemoembolization: Imapct on the Reduction of Contrast Material, Operator Radiation Exposure, Catheter Consumption, and Diagnostic Confidence. Röfo 2018; 190: 513-520

[31] Wohlgemuth WA, Müller-Wille R, Teusch VI et al. The Retrograde Transvenous Push-through Method: a Novel Treatment of Peripheral Arteriovenous Malformations with Dominant Venous Outflow. Cardiovasc Intervent Radiol 2015; 38: 623-631

[32] Puig S, Aref H, Chigot V et al. Classification of venous malformations in children and implications for sclerotherapy. Pediatr Radiol 2003; 33: 99-103

[33] Lee BB, Baumgartner I, Berlien P et al. Diagnosis and Treatment of Venous Malformations Consensus Document of the International Union of Phlebology (IUP): Updated 2013. International Angiology 2015; 34 : 97-149

[34] Abdel Razek AAK, Al-Marsafawy H, Elmansy M et al. Tomography Angiography and Magnetic Resonance Angiography of Congenital Anomalies of Pulmonary Veins. J Comput Assist Tomogr 2019; 43: 399-405

[35] Bajwa A, Wesolowski R, Patel A et al. Assessment of Tissue Perfusion in the Lower Limb, Current Methods and Techniques under Development. Circ Cardiovasc Imaging 2014; 7: 836-843

[36] Masthoff M, Helfen A, Claussen J et al. Use of Multispectral Optoacoustic Tomography to Diagnose Vascular Malformations. JAMA Dermatol 2018; 154: 1457-1462 